\title{
CARRIER-ENVELOPE PHASE CONTROL OF Yb:KGW LASER AND PARAMETRIC AMPLIFIERS
}

\author{
T. Stanislauskas ${ }^{\text {a, b }}$, R. Antipenkov ${ }^{\text {a }}$, V. Martinėnaite ${ }^{\text {a, b }}$, L. Karpavičius ${ }^{\text {a }}$, \\ A. Varanavičius ${ }^{\text {a }}$, P. Mišeikis ${ }^{\text {b }}$, D. Grigaitis ${ }^{\text {b }}$, D. Mikalauskas ${ }^{\text {b }}$, R. Karkockas ${ }^{\text {b }}$, \\ V. Sinkevičius ${ }^{b}$, L. Giniūnas ${ }^{b}$, R. Danielius ${ }^{b}$, T. Balčiūnas ${ }^{c}$, A. Pugžlys ${ }^{c}$, A. Baltuška ${ }^{c}$, \\ and B. Schmidt ${ }^{\mathrm{d}}$ \\ ${ }^{a}$ Department of Quantum Electronics, Faculty of Physics, Vilnius University, Sauletekio 9, LT-10222 Vilnius, Lithuania \\ E-mail: tomas.stanislauskas@ff.stud.vu.lt \\ ${ }^{\mathrm{b}}$ UAB Šviesos konversija (Light Conversion Ltd.), Sauletekio 10, LT-10223 Vilnius, Lithuania \\ ${ }^{c}$ Photonics Institute, Vienna University of Technology, Gusshausstrasse 27-29, A-1040 Vienna, Austria \\ d Menlo Systems GmbH, Am Klopferspitz 19a, 82152 Martinsried, Germany
}

Received 20 September 2012; accepted 3 December 2012

\begin{abstract}
In this paper we present the most recent results on the optimization of the carrier-envelope phase (CEP) stabilization of a Yb:KGW laser system and parametric amplifiers. The implementation of several CEP locking techniques and their combinations allowed us to reduce the RMS phase noise of the oscillator to the values below $100 \mathrm{mrad}$ and demonstrate the operation of the whole laser system with the CEP jitter of $170 \mathrm{mrad}$. The active and passive CEP stabilization for parametric amplifiers was tested. The operation of optical parametric amplifiers in the passive CEP stabilization regime with an additional slow feedback loop providing the CEP jitter as low as 70 mrad over 6 hours was demonstrated.
\end{abstract}

Keywords: carrier-envelope phase, CEP, phase noise, frequency comb, Yb:KGW mode-locked laser

PACS: $42.30 . \mathrm{Rx}, 42.60 . J f, 42.60 . \mathrm{Mi}$

\section{Introduction}

The carrier-envelope phase (CEP) is usually defined as a relative phase between the envelope peak of a pulsed electric field and the closest peak of the carrier wave. Because the highest instantaneous field intensity of a few-cycle pulse depends on the carrier-envelope phase, the controlling of the CEP of ultrashort laser pulses is of prime importance in case of isolated attosecond pulse or high harmonic generation processes [1]. CEP control is also important in the case of much longer pulse durations since it opens path to experiments on the arbitrary optical waveform synthesis [2] and $\mathrm{THz}$ emission control [3].

A number of methods for CEP measurement employing a temporal or spectral domain interfer- ometry and stabilization via feedback controlled modulation of the pump power have been developed in recent years. The locking of the carrier-envelope phase offset in mode-locked Ti:sapphire oscillators using feedback schemes was demonstrated more than a decade ago [4-6]; however, the CEPlocked solid-state oscillators based on the ytterbium doped active elements appeared much later [ [8, 8]. Nowadays, the equipment for stabilizing the CEP of mode-locked oscillators by implementing a feedback loop is commercially available. Recently, the feed-forward set-ups were proposed and demonstrated, in which the phase of the pulses was corrected at the output of the oscillator [9].

However, even if the CEP of the oscillator is controlled, further pulse amplification in a chirped pulse amplifier might deteriorate CEP stability, 
also additional perturbations along the propagation path may appear. The frequency of the phase noise induced by these perturbations is much lower and usually lies in the region below $1 \mathrm{kHz}$. The phase correction in this case can be performed in several ways, for example by introducing additional feedback to the oscillator in order to pre-compensate for the phase drift before amplification, by controlling stretcher or compressor parameters with piezo-electric actuators, by adjusting wedges in the beam path, or by shifting the phase of the pulse by electro-optic, acousto-optic or liquid crystal modulators (see [10] and references therein).

Optical parametric amplifiers (OPAs) are known as flexible tools for the generation of broadly tunable ultrashort pulses. An implementation of different OPA schemes, the methods of non-collinear broadband parametric amplification [11] and chirped pulse parametric amplification [12] allow us to produce pulses with durations down to a few optical cycles [13-16], generate the octave-spanning spectrum pulses in mid-IR with the central wavelength up to $6 \mu \mathrm{m}$ [17], and to achieve the peak powers up to the PW-level [18]. The phase-preserving properties of OPAs have been confirmed in different experimental setups [19-22] and allowed for phase-stable pulse amplification to intensity levels exceeding $1 \mathrm{TW}$ [23]. Another important feature of parametric frequency converters is the possibility to produce the pulses with a phase independent of the input pulse CEP. The passive idler pulse CEP stabilization in a Ti:sapphire laser pumped OPA was demonstrated a decade ago [24] and recently has been proved in OPA systems pumped by femtosecond ytterbium lasers [25, 26].

In this paper we report the improved CEP-stabilized operation of a high average power diodepumped solid-state femtosecond $\mathrm{Yb}$ :KGW master oscillator power amplifier (MOPA) system and present the results on CEP stabilization of $\mathrm{Yb}: \mathrm{KGW}$ MOPA pumped parametric amplifiers.

\section{Carrier-envelope phase locking of the Yb:KGW oscillator}

In our experiments the commercially available diode pumped Yb:KGW MOPA system (Pharos, Light Conversion Ltd.) providing generation of $\sim 190$ fs pulses with an average power up to $6 \mathrm{~W}$ and repetition rate variable in the range of $1 \mathrm{kHz}$ $1 \mathrm{MHz}$ was used. Although CEP locking of every mode-locked oscillator pulse can be achieved in principle, in most cases the locking of the CEP shift per resonator cavity roundtrip is enough. For example, if the CEP shift of precisely $\pi / 2$ per roundtrip is chosen, then every fourth pulse in the oscillator emitted train would be of the exact same phase. This can also be described as setting the carrierenvelope offset (CEO) frequency to $1 / 4$ of the repetition rate frequency of the oscillator [6]. By setting the matching frequency of the pulse-picker, only the pulses with the same carrier-envelope phase are selected for further amplification.

The CEO frequency of the $\mathrm{Yb}: \mathrm{KGW}$ oscillator in our set-up was locked by using the photonic crystal fibre based f-to-2f interferometer and the phaselocked loop (PLL) electronics (XPS800, Menlo Systems $\mathrm{GmbH}$ ). A similar configuration has already been demonstrated to be functional [8]; however, the CEP noise still had to be reduced. The laser power supply had to undergo essential changes in order to isolate it from the electrical noise of the mains. Thus, in the final set-up of our Yb:KGW MOPA system the active elements of the oscillator and amplifier were pumped by the laser diodes which were driven by a specially designed purely analogue power supply featuring a low noise level in the frequency range of $0.1-30 \mathrm{kHz}$.

The feedback signal was used to control the optical power of the pump diodes via direct modulation of laser diode current. The modulation of pump power leads to the variation of per-roundtrip CEP slip in the oscillator due to nonlinear refractive index change in the laser active element. The response of the $\mathrm{Yb}: \mathrm{KGW}$ oscillator to the change of pump power drops rapidly above $\sim 20 \mathrm{kHz}$. Therefore, a custom active high-pass filter was used in order to modify the modulator amplitude and phase transfer function for the enhancement of the oscillator response at higher frequencies. The employment of this filter allowed us to extend the bandwidth of the feedback loop approximately to $120 \mathrm{kHz}$.

The whole set-up for the experiments on CEP locking of laser and OPA pulses is depicted in Fig. 1 . An auxiliary oscillator (OSC) output for CEP measurement was introduced by splitting the oscillator pulse before stretching it and seeding to the regenerative amplifier (RA). For the realization of CEO 


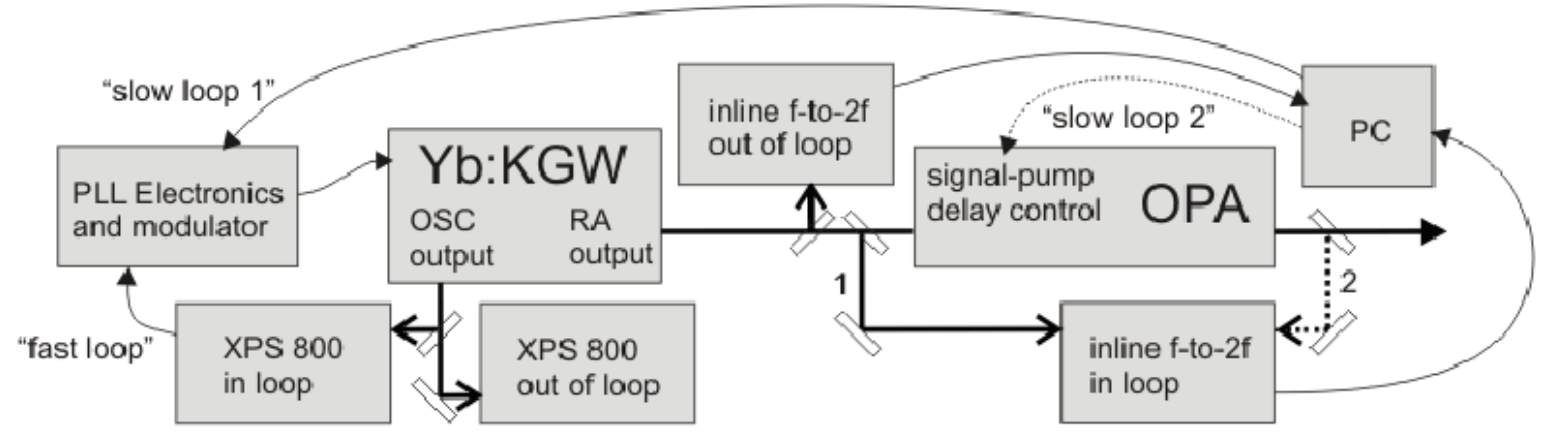

Fig. 1. Experimental set-up. Numbered lines depict the beam path to the inline interferometer for two cases: (1) measuring pulses directly after a regenerative amplifier; (2) measuring pulses after an additional OPA stage.

locking in the $\mathrm{Yb}: \mathrm{KGW}$ oscillator and the measurement of phase jitter we have employed two fto- $2 \mathrm{f}$ interferometers. It is well known that the CEP shift measured by the interferometer that provides a feedback signal to the oscillator, the so-called "inloop" interferometer, does not represent the true value of the output pulse CEP shift. This happens as additional phase noise is introduced in the interferometer itself due to energy-phase coupling [27] and various perturbations in two arms of the interferometers. The compensation for this accumulated noise goes to the feedback loop and is transferred to the oscillator, thus pre-compensating for the interferometer noise by inducing additional phase fluctuations. Therefore, an independent interferometer outside the feedback loop (the so-called "out-of-loop" interferometer) was used simultaneously for the CEP measurements.

The waveform from the phase detector output of the PLL electronics was recorded using the oscilloscope, and the power density spectrum of phase noise was obtained by applying the fast Fourier transformation. To estimate the CEP RMS noise, the acquired noise power density spectra were integrated over the bandwidth from $2.5 \mathrm{Mhz}$ to $10 \mathrm{~Hz}$ according to

$$
\Delta \varphi(f)=\left[2 \int_{10 \mathrm{~Hz}}^{2.5 \mathrm{MHz}} S\left(f^{\prime}\right) d f^{\prime}\right]^{\frac{1}{2}},
$$

where $f$ is frequency, $S$ is phase noise power density spectra, and $\Delta \varphi$ is the RMS phase noise.

The integrated RMS phase noise as low as $56 \mathrm{mrad}$ was obtained using data from the "inloop" interferometer, while measurements with the inactive ("out-of-loop") interferometer resulted in the phase jitter value of $98 \mathrm{mrad}$ (Fig. 2). By isolating the sources of mechanical vibrations and air turbulence, the average level of the oscillator CEP noise in a low frequency range below $500 \mathrm{~Hz}$ was diminished to $-50 \mathrm{dBc} / \mathrm{Hz}$.

The achieved result is a significant improvement to the previously published results on CEP locking

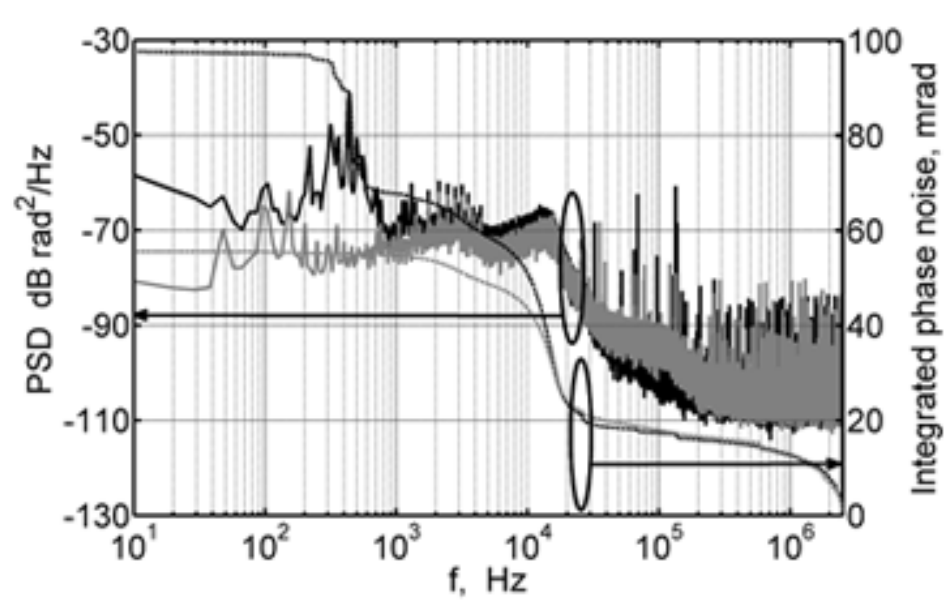

Fig. 2. Measured power spectrum density and integrated phase noise in the CEO-locked $\mathrm{Yb}: \mathrm{KGW}$ oscillator. "In-loop" (grey) and "outof-loop" (black) measurements are presented. 
in femtosecond oscillators with ytterbium doped active elements [ [7, 8] and is comparable to the best reported values for the Ti:sapphire oscillator CEP stabilized using servo-loop schemes [28-30].

\section{CEP stability of the regenerative amplifier}

The repetition rate of the $\mathrm{Yb}: \mathrm{KGW}$ regenerative amplifier was locked to that of the oscillator in such a way that it always picks pulses of the same phase, in our case every $\mathrm{N} \times 4$ th pulse, were $\mathrm{N}$ is an integer. In our set-up an additional common-path f-to- $2 \mathrm{f}$ interferometer was employed for a slow feedback loop which pre-corrected the oscillator pulse phase for the slow phase drift during amplification in the regenerative amplifier. A continuum was generated in a $4 \mathrm{~mm}$ sapphire plate and focused into a $0.3 \mathrm{~mm}$ long $\mathrm{BBO}$ crystal for the second harmonic generation. A single-shot spectral interferogram of spectrally overlapping components of the continuum and its frequency-doubled part was measured by the AvaSpec-3648 spectrometer. A computerbased FFT processing of the f-to- $2 \mathrm{f}$ spectral interferogram was used to extract the CEP value and to send a feedback signal to the phase lock loop electronics of the oscillator. The effect of slow feedback is clearly evident in Fig. 3, which depicts the amplified pulse CEP evolution in time. The slow CEP drift over $1 \mathrm{~min}$ of acquisition in case when the slow feedback loop is turned off leads to $>700 \mathrm{mrad}$ measured phase jitter RMS values. With the slow loop turned on, this value was reduced down to $170 \mathrm{mrad}$.

As our Yb:KGW MOPA system allows for a prompt change of the output pulse repetition rate,

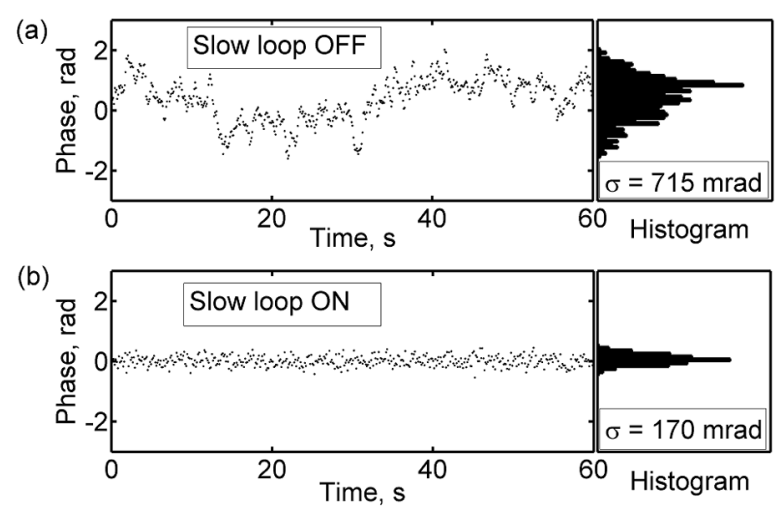

Fig. 3. CE phase noise after RA (a) without and (b) with additional slow feedback loop enabled. we performed a series of CEP stability measurements without slow feedback loop sweeping the laser repetition rate in the range of $1 \mathrm{kHz}-1 \mathrm{MHz}$. In all the cases the CEP jitter measured over $10 \mathrm{~s}$ stayed below $300 \mathrm{mrad}$. This indicates that the Pockels cell acoustic ringing has no significant effect on CEP stability regardless of a dramatic drop in the output pulse contrast at a number of resonant Pockels cell frequencies.

Although f-to-2f interferometers employing white light continuum generation are in commonpath configuration and therefore less sensitive to ambient noise, they still suffer from pulse energy to the measured CE phase coupling [31]. This coupling in the definite energy range can be close to linear, and thus a coupling coefficient can be measured. This coefficient was evaluated by periodical variation of pulse energy at the input of the inline f-to- $2 \mathrm{f}$ interferometer using a variable density neutral filter and retrieving the imposed phase change from the interferogram (Fig. 4). From the linear fit

(a)

(b)
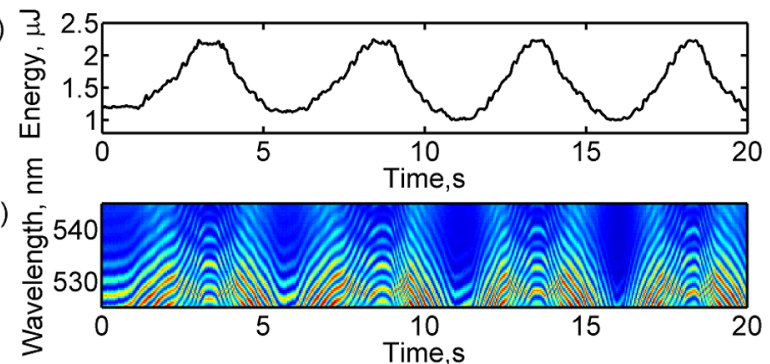

(c)
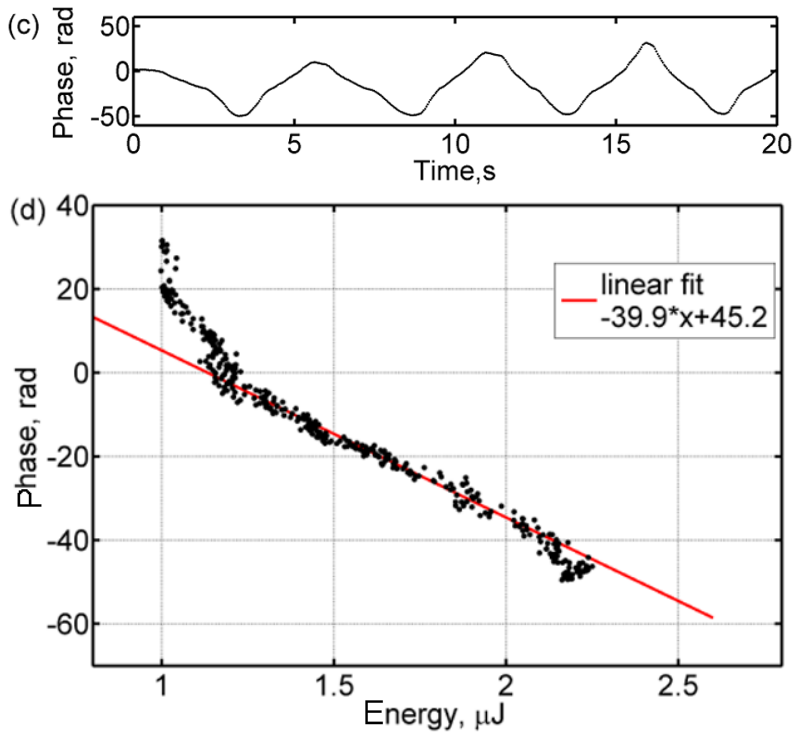

Fig. 4. (a) Pulse energy modulation using a variable density filter. (b) Interference pattern when applying pulse energy modulation over time. (c) Corresponding changes in the measured CEP. (d) Retrieved CEP value versus laser pulse energy. 
of the measured pulse CEP value dependence on incoming pulse energy we found that in our interferometer set-up the $0.1 \%$ increase in pulse energy resulted in a $60 \mathrm{mrad}$ phase shift. The RMS energy variation at the output of our laser system is usually in between $0.1-0.2 \%$ what evidently conceals the true laser CEP stability. We plan to implement the real-time compensation of this effect by the simultaneous measurement of the pulse CEP and energy and we expect that lower phase jitter values will be measured when accounting for the phase-energy coupling in $\mathrm{f}$-to- $2 \mathrm{f}$ interferometers.

\section{Operation of a CEP-locked OPA}

Theoretically, parametric amplification in the conditions of perfect phase matching maintains the phase of the amplified signal pulses [23]. However, for practical purposes, CEP variation caused by environmental instabilities and mechanical vibrations in the experiment set-up should be taken into account and requires to be mitigated.

In our experiment a single-stage collinear OPA based on $1.5 \mathrm{~mm} \mathrm{BBO}$ was pumped by the second harmonic of a CEP-stabilized Pharos laser. The chirped pulses of a broadband continuum generated by focusing a fraction of fundamental pulses into a sapphire plate were used as a CEP-stable seed and directed to a $\mathrm{BBO}$ crystal at $\sim 2^{0}$ with the reference to the pump beam. In order to reduce the spectral width of the amplified pulses, the seed pulses were transmitted through a $12 \mathrm{~mm}$ FS glass plate. The central wavelength of the amplified signal pulses was tunable in a wavelength range from 620 to $1000 \mathrm{~nm}$ by changing the delay between signal and pump pulses and slight adjustment of the BBO crystal angle. The spectrum width of signal pulses was below $80 \mathrm{~nm}$ throughout the OPA tuning range.

The CEP stability of the parametrically amplified signal pulses at $900 \mathrm{~nm}$ was tracked by using the above-described f-to-2f interferometer and CEP retrieval procedures. Figure 5 (a) presents the CEP variation measured in the condition when only the laser oscillator is CEP-locked. We should note that the CEP variation induced by air turbulence or mechanical perturbation of the OPA continuum generator was much more pronounced as compared to the CEP instabilities caused by perturbation of the continuum generator in the $\mathrm{f}$-to- $2 \mathrm{f}$ interferometer.
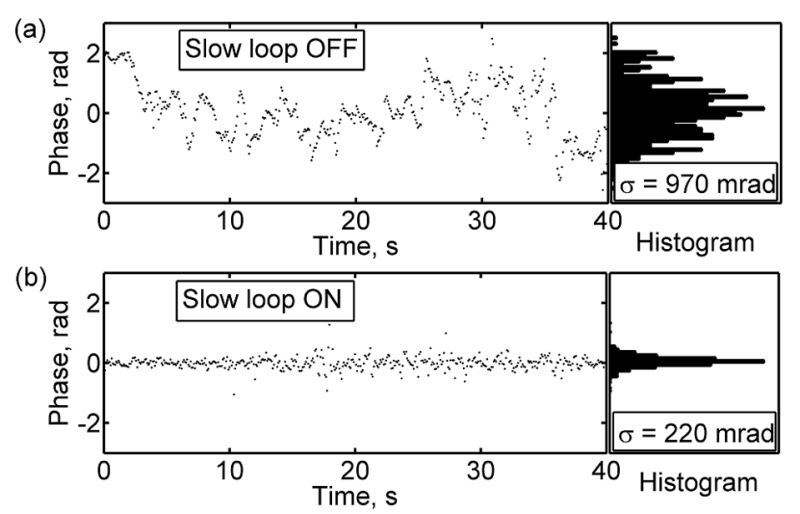

Fig. 5. CEP noise of the OPA output (a) without and (b) with additional slow feedback loop enabled.

The realization of a slow feedback loop by measuring CEP variation after the OPA and sending the feedback signal to the Pharos oscillator through the Menlo Systems' lock-box allowed us to reduce the CEP noise after the OPA from $\sim 1$ rad down to $220 \mathrm{mrad}$ (see Fig. 5(b)). This value is only moderately higher than the phase jitter of the phasestabilized pump laser and the difference can be reasonably explained by the higher OPA output pulse energy and beam pointing instabilities.

The experiments on the passive OPA idler pulse stabilization were carried out using a commercially available three-stage OPA (Orpheus, Light Conversion Ltd.) pumped by the second harmonic Yb:KGW MOPA (Pharos, Light Conversion Ltd.) at the $5 \mathrm{kHz}$ repetition rate.

In order to achieve passive CEP stabilization, only a slight modification was introduced in the OPA set-up: the broadband continuum pulses for the seeding of the OPA were generated in a $4 \mathrm{~mm}$ thick sapphire plate pumped by the pulses of the second harmonic of the $\mathrm{Yb}: \mathrm{KGW}$ laser instead of the fundamental ones. In this arrangement the phases of the seed and pump pulses are identical and consequently the CEP value of idler pulses is constant regardless of any pulse-to-pulse CEP fluctuations in pump laser pulses. We should note that a certain range of OPA tunability was lost due to a rapidly decreasing magnitude of continuum spectra components above $900 \mathrm{~nm}$. However, employment of this configuration ensured reliable generation of idler pulses with the constant CEP value in the wavelength range of 1300-2600 nm. The measurement of CEP stability was performed directing OPA idler pulses to the common-path 
f-to- $2 \mathrm{f}$ interferometer. The supercontinuum was generated by pulses of $1.8 \mu \mathrm{m}$ central wavelength, and the interference was observed in the 700$800 \mathrm{~nm}$ spectral region between the components of supercontinuum and the frequency-doubled part of it from 1.4 to $1.6 \mu \mathrm{m}$. In order to increase the OPA output energy stability the last amplification stage of our OPA was pushed into saturation. The single-shot measurement of the OPA idler pulse CEP jitter without any laser CEP stabilization activated is presented in Fig. 6(a). The CEP stability of $<60 \mathrm{mrad}$ on a short time scale was recorded; however, the phase drift due to the changes in environment conditions on a longer time scale exceeds several radians. This slow CEP drift was compensated employing the additional feedback loop to control the temporal delay between pump and seed pulses in the last OPA stage. Figure 6(c) demonstrates the interference pattern and corresponding idler pulse CEP value variation when the sine-shape of time delay modula-
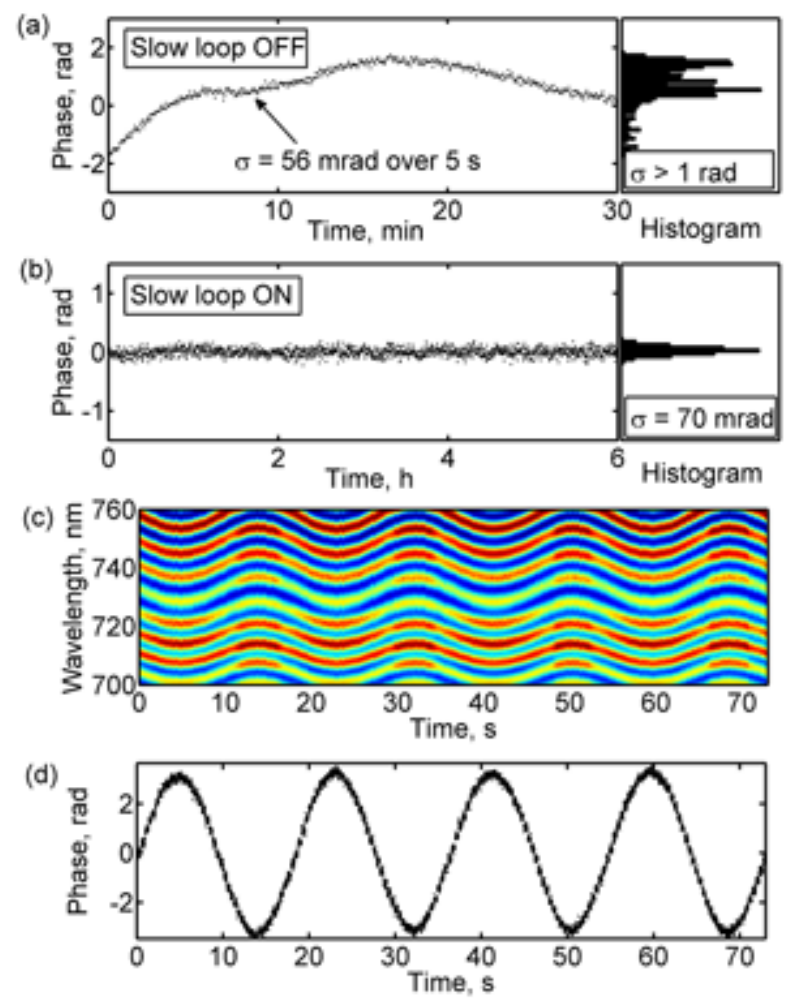

Fig. 6. Long-term CEP variation of OPA idler pulses (a) without and (b) with compensation of slow phase drift. (c) Evolution of the spectral interference pattern. (d) Retrieved idler CEP value for the case of sine-modulation of temporal delay between signal and pump pulses. tion was applied. Additionally, we isolated the whole system from the surrounding air currents and reduced the range of temperature and humidity variation in the laboratory down to a few per cent during the day. As a result, we significantly reduced the CEP drift level and demonstrated CEP-stable OPA operation with the RMS phase error as low as 70 mrad during 6 hours of measurements, which is below the reported values for CEP-stabilized OPA systems.

\section{Conclusions}

In this work we present an optimized CEP stabilization of the Yb:KGW laser system and OPA set-ups pumped by this laser. The oscillator phaselocking stability is improved to sub-100 mrad RMS values, while the whole laser system exhibits a short-term stability of sub-300 mrad in the laser repetition rate range from $1 \mathrm{kHz}$ to $1 \mathrm{MHz}$. The measured low limit of the CEP noise of $170 \mathrm{mrad}$ over a few minutes interval was achieved by implementing an additional slow feedback loop to the oscillator pump. To our knowledge, it is the best result for ytterbium-based amplifier systems.

Additionally, we showed that phase perturbations arising in the OPA and in the pump laser itself can be compensated to a large extent by the measuring of the phase drift at the output of the OPA and sending the feedback signal to the oscillator pump laser diodes. In this case the RMS phase noise was reduced down to $200 \mathrm{mrad}$, which is very close to the CEP jitter value after the regenerative amplifier. This approach is expected to be promising for the minimizing of phase fluctuations in CEP-stable multistage high energy OPCPA systems.

The OPA arranged for the self-phase-stabilized operation showed the sub-60 mrad short-term phase stability of idler pulses generated at $1.8 \mu \mathrm{m}$. After the isolation of the set-up from ambient noise sources and implementation of the slow feedback scheme for the correction of the signalpump delay drift over time, the RMS phase noise as low as $70 \mathrm{mrad}$ over 6 hours of continuous operation was measured. Such characteristics of the laser system and OPA complement each other in the common set-up and could provide necessary tools for experiments requiring CEP-stable pulses. 


\section{Acknowledgements}

This work was partly supported by the Lithuanian Agency for Science, Innovation and Technology (Grant No. 31V-12). We thank J. Matukas and $\mathrm{V}$. Jonkus for kindly providing the spectrum analyser.

\section{References}

[1] A. Baltuska, M. Uiberacker, E. Goulielmakis, R. Kienberger, V.S. Yakovlev, T. Udem, T.W. Hansch, and F. Krausz, Phase-controlled amplification of few-cycle laser pulses, IEEE J. Select. Top. Quant. Electron. 9(4), 972-989 (2003).

[2] S.T. Cundiff and A.M. Weiner, Optical arbitrary waveform generation, Nat. Photon. 4(11), 760-766 (2010).

[3] T. Balciunas, D. Lorenc, and M. Ivanov, Tunable $\mathrm{THz}$ generation with a CEP-stable muticolor OPA, in: High Intensity Lasers and High-Field Phenomena, paper HWC3, 2011.

[4] R. Holzwarth, T. Udem, T. Hansch, J. Knight, W. Wadsworth, and P. Russell, Optical frequency synthesizer for precision spectroscopy, Phys. Rev. Lett. 85(11), 2264-2267 (2000).

[5] A. Apolonski, A. Poppe, G. Tempea, C. Spielmann, T. Udem, R. Holzwarth, T. Hansch, and F. Krausz, Controlling the phase evolution of few-cycle light pulses, Phys. Rev. Lett. 85(4), 740-743 (2000).

[6] D.J. Jones, Carrier-envelope phase control of femtosecond mode-locked lasers and direct optical frequency synthesis, Science 288(5466), 635-639 (2000).

[7] S.A. Meyer, J.A. Squier, and S.A. Diddams, Diodepumped $\mathrm{Yb}: \mathrm{KYW}$ femtosecond laser frequency comb with stabilized carrier-envelope offset frequency, Eur. J. Phys. D 48(1), 19-26 (2008).

[8] T. Balčiūnas, O.D. Mücke, P. Mišeikis, G. Andriukaitis, A. Pugžlys, L. Giniūnas, R. Danielius, R. Holzwarth, and A. Baltuška, Carrier envelope phase stabilization of a Yb:KGW laser amplifier, Opt. Lett. 36(16), 3242-3244 (2011).

[9] S. Koke, C. Grebing, H. Frei, A. Anderson, A. Assion, and G. Steinmeyer, Direct frequency comb synthesis with arbitrary offset and shotnoise-limited phase noise, Nat. Photon. 4(7), 462465 (2010).

[10]O. Gobert, P.M. Paul, J.F. Hergott, O. Tcherbakoff, F. Lepetit, P.D. 'Oliveira, F. Viala, and M. Comte, Carrier-envelope phase control using linear electrooptic effect, Opt. Express 19(6), 5410-5418 (2011).

[11] G.M. Gale, M. Cavallari, T.J. Driscoll, and F. Hache, Sub-20-fs tunable pulses in the visible from an $82-\mathrm{MHz}$ optical parametric oscillator, Opt. Lett. 20(14), 1562-1564 (1995).
[12] A. Dubietis, G. Jonušauskas, and A.P. Piskarskas, Powerful femtosecond pulse generation by chirped and stretched pulse parametric amplification in BBO crystal, Opt. Commun. 88(4-6), 437-440 (1992).

[13] K. Okamura and T. Kobayashi, Octave-spanning carrier-envelope phase stabilized visible pulse with sub-3-fs pulse duration, Opt. Lett. 36(2), 226-228 (2011).

[14] D. Brida, G. Cirmi, C. Manzoni, S. Bonora, P. Villoresi, S. De Silvestri, and G. Cerullo, Subtwo-cycle light pulses at $1.6 \mu \mathrm{m}$ from an optical parametric amplifier, Opt. Lett. 33(7), 741-743 (2008).

[15]D. Brida, M. Marangoni, C. Manzoni, S. De Silvestri, and G. Cerullo, Two-optical-cycle pulses in the mid-infrared from an optical parametric amplifier, Opt. Lett. 33(24), 2901-2903 (2008).

[16]R. Antipenkov, A. Varanavičius, A. Zaukevičius, and A.P. Piskarskas, Femtosecond Yb:KGW MOPA driven broadband NOPA as a frontend for TW few-cycle pulse systems, Opt. Express 19(4), 3519-3524 (2011).

[17]G. Andriukaitis, S. Alisauskas, A. Pugzlys, A. Baltuska, L. Tan, H.-W.J. Lim, P.B. Phua, K. Balskus, and A. Michailovas, Broadband $6 \mu \mathrm{m}$ OPA driven by $\mathrm{Yb}: \mathrm{CaF} 2$ DPSSL system - OSA technical digest (online), in: CLEO: Science and Innovations, paper CF3B.6 (Optical Society of America, 2012).

[18] V.V. Lozhkarev, G.I. Freidman, V.N. Ginzburg, E.V. Katin, E.A. Khazanov, A.V. Kirsanov, G.A. Luchinin, A.N. Mal'shakov, M.A. Martyanov, O.V. Palashov, A.K. Poteomkin, A.M. Sergeev, A.A. Shaykin, and I.V. Yakovlev, Compact 0.56 Petawatt laser system based on optical parametric chirped pulse amplification in $\mathrm{KD}^{\star} \mathrm{P}$ crystals, Laser Phys. Lett. 4(6), 421-427 (2007).

[19]P. Baum, S. Lochbrunner, J. Piel, and E. Riedle, Phase-coherent generation of tunable visible femtosecond pulses, Opt. Lett. 28(3), 185-187 (2003).

[20]R.T. Zinkstok, S. Witte, W. Hogervorst, and K.S.E. Eikema, High-power parametric amplification of 11.8 -fs laser pulses with carrier-envelope phase control, Opt. Lett. 30(1), 78-80 (2005).

[21]C.P. Hauri, P. Schlup, G. Arisholm, J. Biegert, and U. Keller, Phase-preserving chirped-pulse optical parametric amplification to $17.3 \mathrm{fs}$ directly from a Ti:sapphire oscillator, Opt. Lett. 29(12), 13691371 (2004).

[22] G. Cirmi, C. Manzoni, D. Brida, S. De Silvestri, and G. Cerullo, Carrier-envelope phase stable, few-optical-cycle pulses tunable from visible to near IR, J. Opt. Soc. Am. B 25(7), B62-B69 (2008).

[23] A. Renault, D.Z. Kandula, S. Witte, A.L. Wolf, R.T. Zinkstok, W. Hogervorst, and K.S.E. Eikema, 
Phase stability of terawatt-class ultrabroadband parametric amplification, Opt. Lett. 32(16), 23632365 (2007).

[24] A. Baltuška, T. Fuji, and T. Kobayashi, Controlling the carrier-envelope phase of ultrashort light pulses with optical parametric amplifiers, Phys. Rev. Lett. 88(13), 4-7 (2002).

[25] O.D. Mücke, D. Sidorov, P. Dombi, A. Pugžlys, A. Baltuška, S. Ališauskas, V. Smilgevičius, J. Pocius, L. Giniūnas, R. Danielius, and N. Forget, Scalable Yb-MOPA-driven carrier-envelope phase-stable few-cycle parametric amplifier at $1.5 \mu \mathrm{m}$, Opt. Lett. 34(2), 118-120 (2009).

[26] C. Homann, M. Bradler, M. Förster, P. Hommelhoff, and E. Riedle, Carrier-envelope phase stable sub-two-cycle pulses tunable around $1.8 \mu \mathrm{m}$ at $100 \mathrm{kHz}$, Opt. Lett. 37(10), 1673-1675 (2012).

[27]H. Wang, M. Chini, E. Moon, H. Mashiko, C. Li, and Z. Chang, Coupling between energy and phase in hollow-core fiber based f-to-2f interferometers, Opt. Express 17(14), 12082-12089 (2009).

[28] S.T. Cundiff and J. Ye, Phase stabilization of modelocked lasers, J. Mod. Opt. 52(2-3), 201-219 (2005).

[29]G. Gademann, F. Plé, P.-M. Paul, and M.J.J. Vrakking, Carrier-envelope phase stabilization of a terawatt level chirped pulse amplifier for generation of intense isolated attosecond pulses, Opt. Express 19(25), 24922-24932 (2011).

[30]E.B. Kim, J.-H. Lee, W.-K. Lee, T.T. Luu, and C.H. Nam, Long-term maintenance of the carrierenvelope phase coherence of a femtosecond laser, Opt. Express 18(25), 26365-26372 (2010).

[31]C. Li, E. Moon, H. Wang, H. Mashiko, C.M. Nakamura, J. Tackett, and Z. Chang, Determining the phase-energy coupling coefficient in carrier-envelope phase measurements, Op. Lett. 32(7), 796-798 (2007).

\section{Yb:KGV LAZERIO IR OPTINIŲ PARAMETRINIUU STIPRINTUVŲ IMPULSŲ GAUBTINĖS FAZINIO POSLINKIO VALDYMAS}

T. Stanislauskas a, b, R. Antipenkov a, V. Martinėnaite ${ }^{\text {a,b }}$, L. Karpavičius a, A. Varanavičius a, P. Mišeikis ${ }^{b}$, D. Grigaitis ${ }^{b}$, D. Mikalauskas ${ }^{b}$, R. Karkockas ${ }^{b}$, V. Sinkevičius ${ }^{b}$, L. Giniūnas ${ }^{\text {b }}$, R. Danielius ${ }^{b}$, T. Balčiūnas ${ }^{c}$, A. Pugžlys ${ }^{c}$, A. Baltuška ${ }^{c}$, B. Schmidt ${ }^{d}$

a Vilniaus universiteto Fizikos fakulteto Kvantinès elektronikos katedra, Vilnius, Lietuva

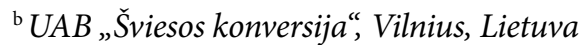

${ }^{c}$ Vienos technologijos universiteto Fotonikos institutas, Viena, Austrija

d „Menlo Systems GmbH“, Martinsried, Vokietija

\section{Santrauka}

Pristatomi naujausi Yb:KGV lazerio bei optinių parametrinių stiprintuvų (OPS) impulsų gaubtinès fazinio poslinkio (GFP) stabilizavimo rezultatai. Panaudojus kelis fazès stabilizavimo metodus bei jų derinius, lazerio osciliatoriaus impulsu GFP nuokrypius pavyko apriboti iki mažesnių kaip 100 mrad reikšmių.
Minimali išmatuota GFP nuokrypio vertè visai lazerinei sistemai - 170 mrad. Parametriniais stiprintuvais išbandyti tiek aktyvūs, tiek ir pasyvūs GFP stabilizavimo būdai. Panaudojus papildomą grị̌tamąji ryšị, pasyviai stabilizuotų skirtuminių OPS impulsų fazès vidutinis kvadratinis nuokrypis 6 val. neviršijo $70 \mathrm{mrad}$. 